19

\title{
Тепловое расширение и теплоемкость нанокристаллического и крупнокристаллического сульфида серебра $\mathrm{Ag}_{2} \mathrm{~S}$
}

\author{
(С) С.И. Садовников, А.И. Гусев \\ Институт химии твердого тела УрО РАН, \\ Екатеринбург, Россия \\ ฯ E-mail: gusev@ihim.uran.ru \\ (Поступила в Редакцию 2 марта 2017 г.)
}

\begin{abstract}
Впервые методами дилатометрии и дифференциальной сканирующей калориметрии изучены тепловое расширение и теплоемкость крупнокристаллического и нанокристаллического сульфида серебра $\mathrm{Ag}_{2} \mathrm{~S}$ в интервале температур 290-970 К. Установлено, что коэффициент термического расширения и теплоемкость нанокристаллического сульфида серебра в изученной области температур больше, чем в случае крупнокристаллического сульфида. Установлено, что превращения акантита $\alpha-\mathrm{Ag}_{2} \mathrm{~S}$ в аргентит $\beta-\mathrm{Ag}_{2} \mathrm{~S}$ и аргентита $\beta-\mathrm{Ag}_{2} \mathrm{~S}$ в фазу $\gamma-\mathrm{Ag}_{2} \mathrm{~S}$ являются фазовыми переходами первого рода, определены температуры и энтальпии этих превращений.
\end{abstract}

Исследование выполнено в ИХТТ УрО РАН за счет гранта Российского научного фонда (проект РНФ № 14-23-00025).

DOI: 10.21883/FTT.2017.09.44863.061

\section{1. Введение}

Сульфид серебра $\mathrm{Ag}_{2} \mathrm{~S}$ может использоваться для преобразования солнечной энергии в электричество [1-4] и для инфракрасной техники $[5,6]$. Для применения сульфида серебра в инфракрасной технике и преобразователях солнечной энергии нужна информация об изменении коэффициента термического расширения в зависимости от температуры.

Сульфид серебра $\mathrm{Ag}_{2} \mathrm{~S}$ имеет три полиморфные модификации [7]. Низкотемпературная моноклинная фаза $\alpha-\mathrm{Ag}_{2} \mathrm{~S}$ (акантит) существует при температуре $<450 \mathrm{~K}$. Кубический аргентит $\beta-\mathrm{Ag}_{2} \mathrm{~S}$ имеет объемно центрированную решетку атомов серы и существует в температурном интервале $452-859 \mathrm{~K}$. Высокотемпературная кубическая фаза $\gamma$ - $\mathrm{Ag}_{2} \mathrm{~S}$ с гранецентрированной кубической подрешеткой атомов серы стабильна при температуре от $\sim 860 \mathrm{~K}$ до температуры плавления. Для технического применения наибольший интерес представляют низкотемпературные фазы акантит и аргентит.

Акантит $\alpha-\mathrm{Ag}_{2} \mathrm{~S}$ имеет моноклинную (пр.гр. $P 2_{1} / c$ $\left.\left(P 12_{1} / c 1\right)\right)$ структуру [8-10]. Согласно [9], крупнокристаллический порошок сульфида серебра со средним размером частиц $\sim 500 \mathrm{~nm}$ и более является стехиометрическим. Элементарная ячейка акантита $\alpha-\mathrm{Ag}_{2} \mathrm{~S}$ включает четыре формульные единицы $\mathrm{Ag}_{2} \mathrm{~S}(z=4)$. Тщательное исследование нанокристаллического сульфида серебра позволило обнаружить, что он имеет такую же моноклинную (пр.гр. $P 2_{1} / c$ ) структуру типа акантита, но является нестехиометрическим и имеет состав $\mathrm{Ag}_{1.93} \mathrm{~S}$ [10].

Сульфид серебра при температуре выше $433 \mathrm{~K}$ содержит кубическую (пр. гр. № $229-\operatorname{Im} \overline{3} m(I 4 / m \overline{3} 2 / m)$ $\left.\left(\mathrm{O}_{h}^{9}\right)\right)$ фазу со структурой типа аргентита $\beta-\mathrm{Ag}_{2} \mathrm{~S}$. Элементарная ячейка аргентита $\beta-\mathrm{Ag}_{2} \mathrm{~S}$ включает две фор- мульные единицы $\mathrm{Ag}_{2} \mathrm{~S}(z=2)$. По высокотемпературным рентгеновским данным [11] четыре атома $\mathrm{Ag}$ статистически распределены по 54 позициям 6(b) и $48(j)$ с вероятностями заполнения $\sim 0.097$ и $\sim 0.0715$ соответственно. Структура аргентита $\beta-\mathrm{Ag}_{2} \mathrm{~S}$ подробно описана в работах $[12,13]$ и приложенных к ним файлах Crystallographic information file (CCDC reference number 1062400) и ESI соответственно. По данным [12,13] четыре атома серебра статистически размещены на позициях $6(b)$ и $48(j)$ со степенями заполнения $0.0978(7)$ и $0.0711(0)$.

Сульфид серебра при температуре выше $\sim 860 \mathrm{~K}$ содержит кубическую (пр.гр. № $225-F m \overline{3} m$ $\left.(F 4 / m \overline{3} 2 / m)\left(\mathrm{O}_{h}^{5}\right)\right)$ фазу $\gamma-\mathrm{Ag}_{2} \mathrm{~S}$. Элементарная ячейка фазы $\gamma-\mathrm{Ag}_{2} \mathrm{~S}$ включает четыре формульные единицы $\mathrm{Ag}_{2} \mathrm{~S}(z=4)$. При температуре $923 \mathrm{~K}$ восемь атомов $\mathrm{Ag}$ статистически распределены по 88 позициям $8(c), 32(f)$ и $48(i)$ с вероятностями заполнения $\sim 0.088, \sim 0.15$ и $\sim 0.027$ соответственно [11].

В равновесных условиях при температуре $\sim 448-453 \mathrm{~K}$ происходит фазовое превращение моноклинного акантита $\alpha-\mathrm{Ag}_{2} \mathrm{~S}$ в аргентит $\beta-\mathrm{Ag}_{2} \mathrm{~S}$, а при температуре $\sim 845-860 \mathrm{~K}$ аргентит $\beta-\mathrm{Ag}_{2} \mathrm{~S}$ переходит в фазу $\gamma-\mathrm{Ag}_{2} \mathrm{~S}[7,14-16]$.

До последнего времени немногочисленные сведения о фазовых превращениях акантит-аргентит были получены только на объемных (bulk) образцах крупнозернистого сульфида серебра $\mathrm{Ag}_{2} \mathrm{~S}$ [14-16]. Например, фазовое превращение $\beta-\mathrm{Ag}_{2} \mathrm{~S}-\gamma-\mathrm{Ag}_{2} \mathrm{~S}$ изучалось в работе [15] при измерении теплоемкости и в работе [16] при измерении энтальпии крупнозернистого сульфида серебра $\mathrm{Ag}_{2} \mathrm{~S}$. Исследование фазового превращения акантит-аргентит в нанокристаллическом сульфиде серебра методами электронной микроскопии и ДТА-ДТГ (ДТА - дифференциальный термический 
Состав реакционных смесей для синтеза сульфида серебра, площадь удельной поверхности $S_{\text {sp }}$ и средний размер $D$ частиц порошков $\mathrm{Ag}_{2} \mathrm{~S}$

\begin{tabular}{|c|c|c|c|c|c|c|}
\hline \multirow{2}{*}{$\begin{array}{c}\text { Номер } \\
\text { образца }\end{array}$} & \multicolumn{3}{|c|}{ Концентрация реагентов в реакционной смеси, $\mathrm{mol} \cdot 1^{-1}$} & \multirow{2}{*}{$\begin{array}{c}S_{\mathrm{sp}}( \pm 0.20) \\
\mathrm{m}^{2} \cdot \mathrm{g}^{-1}\end{array}$} & \multicolumn{2}{|c|}{$D, \mathrm{~nm}$} \\
\hline & $\mathrm{AgNO}_{3}$ & $\mathrm{Na}_{2} \mathrm{~S}$ & $\mathrm{Na}_{3} \mathrm{C}_{6} \mathrm{H}_{5} \mathrm{O}_{7}$ & & БЭТ & Рентген \\
\hline 1 & 0.05 & 0.1 & 0.025 & $1.9 \pm 0.1$ & $430 \pm 10$ & - \\
\hline 2 & 0.05 & 0.050 & 0.1 & $1.8 \pm 0.1$ & $460 \pm 10$ & - \\
\hline 3 & 0.05 & 0.025 & 0.1 & - & - & $66 \pm 8$ \\
\hline 4 & 0.05 & 0.025 & 0.025 & $12.4 \pm 0.1$ & $67 \pm 5$ & $54 \pm 6$ \\
\hline
\end{tabular}

анализ, ДТГ - дифференциальная термогравиметрия) выполнили авторы $[12,17]$. Недавно $[13,18]$ методом высокотемпературной рентгеновской дифракции выполнено in situ исследование теплового расширения крупнокристаллического и нанокристаллического сульфида серебра: моноклинного акантита $\alpha-\mathrm{Ag}_{2} \mathrm{~S}$ и кубического аргентита $\beta-\mathrm{Ag}_{2} \mathrm{~S}$.

Сведения о тепловом расширении сульфида серебра крайне ограничены, хотя такие данные нужны для применения $\mathrm{Ag}_{2} \mathrm{~S}$ при повышенной температуре. Согласно [19], коэффициент линейного термического расширения акантита $\alpha_{\text {ac }}$ равен $\sim 20 \cdot 10^{-6} \mathrm{~K}^{-1}$. Интервал температур, которому соответствует этот коэффициент, и метод его измерения в работе [19] не указаны. Согласно [20], относительные удлинения акантита при температуре от 293 до $450 \mathrm{~K}$ и аргентита при температуре от $\sim 460$ до $570 \mathrm{~K}$ линейно зависят от температуры. Из этого следует, что коэффициенты линейного термического расширения акантита и аргентита в соответствующих температурных интервалах не зависят от температуры. Действительно, коэффициент линейного термического расширения акантита в температурном интервале $293-450 \mathrm{~K}$ равен $16.8 \cdot 10^{-6} \mathrm{~K}^{-1}$, a коэффициент линейного термического расширения аргентита при температуре от $\sim 460$ до $570 \mathrm{~K}$ равен $45.8 \cdot 10^{-6} \mathrm{~K}^{-1}$ [20]. По данным высокотемпературной рентгеновской дифракции $[13,18]$ коэффициент линейного расширения крупнокристаллического акантита в области температур 300-433 К увеличивается от $\sim 18.4 \cdot 10^{-6}$ до $\sim 24.0 \cdot 10^{-6} \mathrm{~K}^{-1}$. Коэффициент линейного термического расширения нанокристаллического акантита в этой же области температур примерно на $\sim 25 \%$ больше, чем аналогичный коэффициент крупнокристаллического акантита. Из результатов измерения температурной зависимости периода кристаллической решетки аргентита следует, что коэффициент линейного термического расширения аргентита при увеличении температуры от 443 до $623 \mathrm{~K}$ уменьшается от $\sim 55 \cdot 10^{-6}$ до $\sim 42 \cdot 10^{-6} \mathrm{~K}^{-1}[13,18]$.

Данных о тепловом расширении кубической фазы $\gamma-\mathrm{Ag}_{2} \mathrm{~S}$ в литературе нет.

В настоящей работе впервые проведены прямые дилатометрические измерения теплового расширения крупнокристаллического и нанокристаллического сульфида серебра в областях существования моноклинного акан- тита $\alpha-\mathrm{Ag}_{2} \mathrm{~S}$, аргентита $\beta-\mathrm{Ag}_{2} \mathrm{~S}$ и фазы $\gamma-\mathrm{Ag}_{2} \mathrm{~S}$, а также теплоемкости нанокристаллического сульфида серебра в области температур 300-930 K.

\section{2. Эксперимент}

Порошки сульфида серебра с разным размером частиц синтезировались химическим осаждением из водных растворов нитрата серебра $\mathrm{AgNO}_{3}$, сульфида натрия $\mathrm{Na}_{2} \mathrm{~S}$ и цитрата натрия $\mathrm{Na}_{3} \mathrm{C}_{6} \mathrm{H}_{5} \mathrm{O}_{7} \equiv \mathrm{Na}_{3} \mathrm{Cit}$. Размер частиц регулировался путем изменения концентраций реагентов и продолжительностью нахождения осадков в реакционных смесях. Методика синтеза описана ранее $[9,10,21,22]$. Заметим, что химическое осаждение сульфидов из водных растворов является частным случаем one-pot синтеза [23], который позволяет синтезировать неорганические наночастицы непосредственно в водной среде. Осажденные порошки $\mathrm{Ag}_{2} \mathrm{~S}$ промывались дистиллированной водой для удаления растворимых примесей, фильтровались и сушились при 323 К. Состав реакционных смесей и средний размер частиц синтезированных порошков $\mathrm{Ag}_{2} \mathrm{~S}$ приведены в таблице.

Синтезированные порошки сульфида серебра исследовались на дифрактометре STADI-P (STOE) в $\mathrm{Cu} K_{\alpha}$-излучении в интервале углов $2 \theta=20-95^{\circ}$ с шагом $\Delta(2 \theta)=0.02^{\circ}$ и временем экспозиции $10 \mathrm{~s}$ в каждой точке. Определение параметров кристаллической решетки и окончательное уточнение структуры синтезированных порошков сульфида серебра проводились с помощью программного пакета X'Pert Plus [24].

Микроструктура порошков $\mathrm{Ag}_{2} \mathrm{~S}$ изучалась методом сканирующей электронной микроскопии на микроскопе JEOL-JSM LA 6390 по методике, описанной в работах $[25,26]$.

Средний размер $D$ частиц в синтезированных порошках сульфида серебра оценивался методом рентгеновской дифракции по уширению $\beta(2 \theta)$ дифракционных отражений [27,28], по величине удельной поверхности $S_{\mathrm{sp}}$, измеренной методом Брунауэра-Эммета-Теллера (БЭТ), и по данным сканирующей электронной микроскопии.

Коэффициент термического расширения измерялся на цилиндрических образцах диаметром 5 и $10 \mathrm{~mm}$, спрессованных из синтезированных порошков $\mathrm{Ag}_{2} \mathrm{~S}$ под давлением $\sim 260 \mathrm{MPa}$. Длина образцов составляла 
от 3.5 до $6.3 \mathrm{~mm}$. Измерения проводились на дилатометре Linseis L75/1250 (USA) в вакууме $0.0026 \mathrm{~Pa}$ $\left(2 \cdot 10^{-5} \mathrm{~mm} \mathrm{Hg}\right)$ в интервале температур $293-985 \mathrm{~K}$ с шагом $1 \mathrm{~K}$ и дилатометре NETZSCH DIL 402C в атмосфере гелия Не при температуре от 293 до $923 \mathrm{~K}$ с шагом $0.5 \mathrm{~K}$. Скорость нагрева составляла $4 \mathrm{~K} \cdot \mathrm{min}^{-1}$.

Теплоемкость порошков сульфида серебра измерялась на термоанализаторе STA 449 в атмосфере аргона при нагреве до $\sim 930 \mathrm{~K}$ с шагом $0.5 \mathrm{~K}$.

\section{3. Влияние температуры на тепловое расширение сульфида серебра}

Рентгенограммы исходных порошков сульфида серебра, измеренные при температуре $293 \mathrm{~K}$, показаны на рис. 1. Количественное уточнение рентгенограмм и сравнение с данными $[9,10]$ показали, что все порошки являются однофазными и содержат набор дифракционных отражений моноклинного (пр. гр. $P 2_{1} / c$ ) акантита $\alpha-\mathrm{Ag}_{2} \mathrm{~S}$. Рентгенограммы нанокристаллических сульфидов серебра (рис. 1, образцы № 3 и 4) содержат набор уширенных дифракционных отражений. Оценка среднего размера $D$ областей когерентного рассеяния была проведена по уширению неперекрывающихся ди-

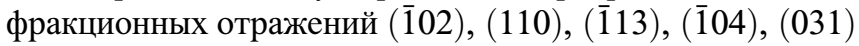

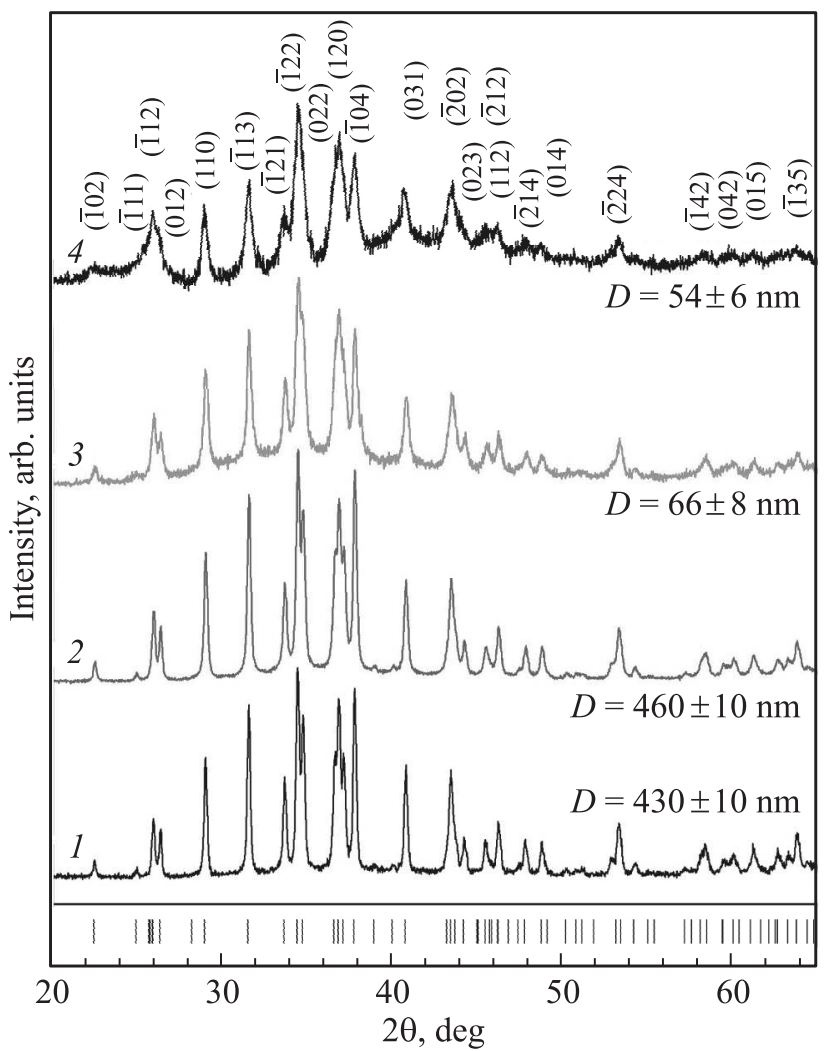

Рис. 1. Рентгенограммы порошков сульфида серебра $\mathrm{Ag}_{2} \mathrm{~S}$ при температуре $293 \mathrm{~K}$. Номера кривых соответствуют номерам образцов в таблице. Положение дифракционных отражений акантита $\alpha-\mathrm{Ag}_{2} \mathrm{~S}$ показано вертикальными штрихами.
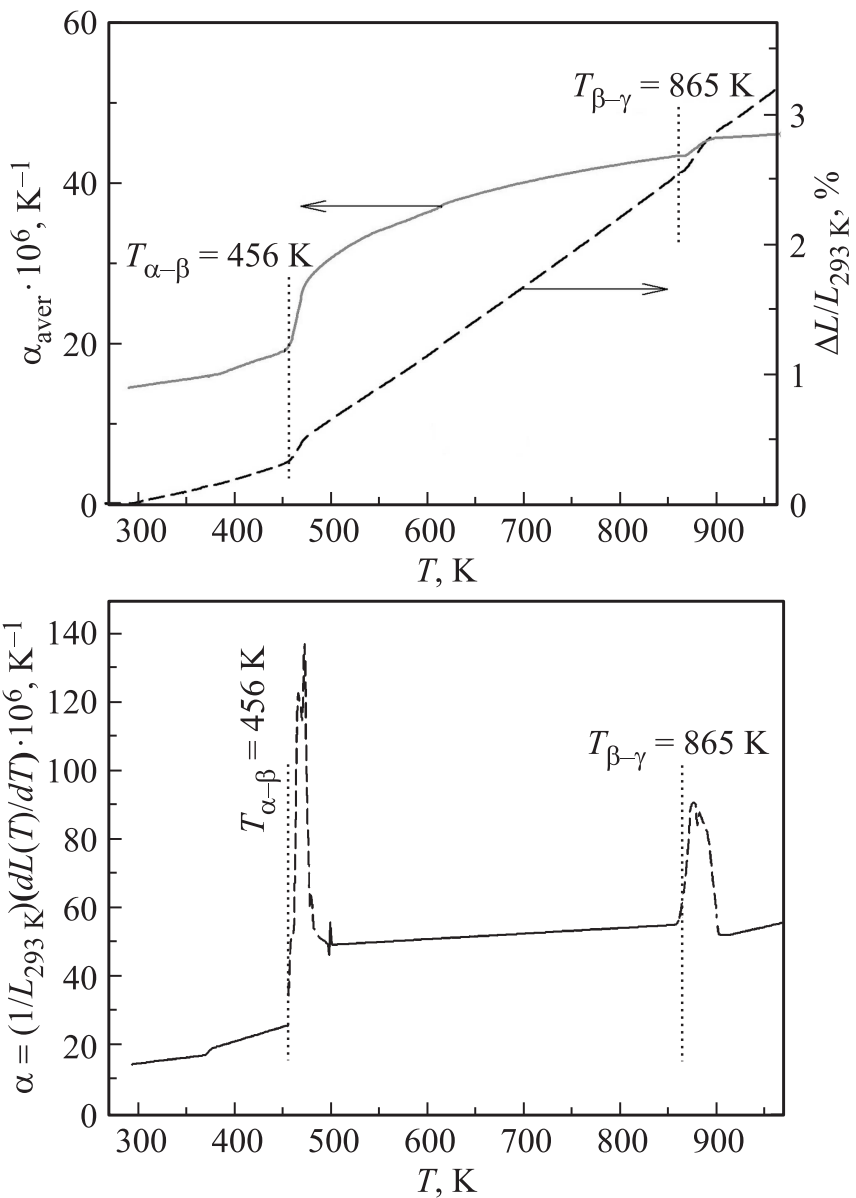

Рис. 2. Влияние температуры на относительное удлинение $\Delta L / L_{293 \mathrm{~K}}$, средний коэффициент термического расширения $\alpha_{\text {aver }}$ и коэффициент термического расширения $\alpha(T)$ образца № 1. Области разрыва коэффициента $\alpha(T)$ показаны штриховыми линиями. Температуры $T_{\alpha-\beta}$ и $T_{\beta-\gamma}$ переходов $\alpha-\mathrm{Ag}_{2} \mathrm{~S}-\beta-\mathrm{Ag}_{2} \mathrm{~S}$ и $\beta-\mathrm{Ag}_{2} \mathrm{~S}-\gamma-\mathrm{Ag}_{2} \mathrm{~S}$ отмечены вертикальными пунктирными линиями. Средний размер частиц в исходном порошке № 1 сульфида серебра равен $430 \mathrm{~nm}$.

и (014). Согласно этим оценкам, в синтезированных нанопорошках акантита (образцы № 3 и 4) средний размер $D$ частиц составляет $\sim 66$ и $\sim 54 \mathrm{~nm}$. Это согласуется с оценкой среднего размера $D$ частиц по площади удельной поверхности $S_{\mathrm{sp}}$ (см. таблицу).

Влияние нагрева на относительное удлинение $\Delta L / L_{293 \mathrm{~K}}$ образцов сульфида серебра, спрессованных из порошков $\mathrm{Ag}_{2} \mathrm{~S}$, осажденных из реакционных смесей № 1-3 (см. таблицу), показано на рис. 2-4.

Линейный коэффициент термического расширения $\alpha_{\text {aver }}$ определялся как средний коэффициент в температурном интервале между начальной температурой $293 \mathrm{~K}$ и температурой измерения $T$

$$
\alpha_{\text {aver }}(T)=\frac{\Delta L}{L_{293 \mathrm{~K}} \Delta T}=\frac{L(T)-L_{293 \mathrm{~K}}}{L_{293 \mathrm{~K}}(T-293)},
$$

где $L(T), L_{293} \mathrm{~K}$ - длина образца при температуре $T$ и при начальной температуре $T_{0}=293 \mathrm{~K}$. 

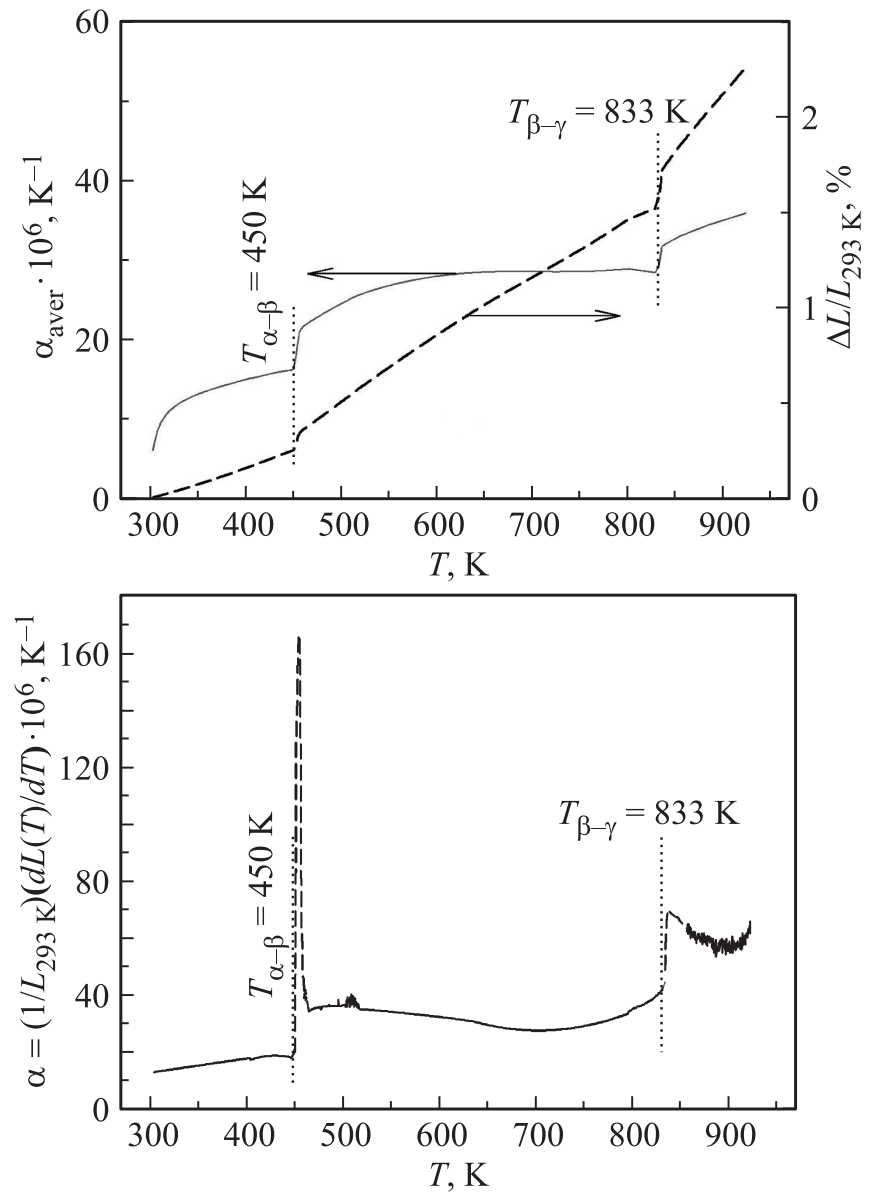

Рис. 3. Температурные зависимости относительного удлинения $\Delta L / L_{293}$ к, среднего коэффициента термического расширения $\alpha_{\text {aver }}$ и коэффициента термического расширения $\alpha(T)$ образца № 2. Области разрыва коэффициента $\alpha(T)$ показаны штриховыми линиями. Температуры переходов отмечены вертикальными пунктирными линиями. Средний размер частиц в исходном порошке № 2 сульфида серебра равен $460 \mathrm{~nm}$.

Точное значение коэффициента термического расширения $\alpha(T)$ при температуре $T$ находили численным дифференцированием температурной зависимости удлинения $L(T)$ как

$$
\alpha(T)=\frac{1}{L_{293 \mathrm{~K}}} \frac{d L(T)}{d T} .
$$

Определение коэффициента термического расширения $\alpha(T)$ в окрестности температур превращений $T_{\alpha-\beta}$ или $T_{\beta-\gamma}$ позволяет выяснить род фазового перехода.

Действительно, линейный коэффициент термического расширения $\alpha(T)$ связан с теплоемкостью $C_{V}$ соотношением [29]

$$
\alpha(T)=\frac{\gamma}{3 B} \frac{C_{V}(T)}{v_{m}},
$$

где $B-$ модуль всестороннего сжатия, $v_{m}-$ молярный объем, $\gamma-$ постоянная Грюнайзена. В случае фазового перехода первого рода при температуре перехода свободная энергия испытывает излом, на температурных зависимостях энтропии и энтальпии наблюдаются скачки, а теплоемкость и коэффициент термического расширения $\alpha(T)$, как следует из (3), в точке перехода испытывают разрыв. Что касается температурной зависимости среднего коэффициента термического расширения $\alpha_{\mathrm{aver}}(T)$, то на ней в точке перехода будут наблюдаться размытые скачки. При фазовых переходах второго рода энтропия изменяется непрерывно и теплота (энтальпия) перехода отсутствует, поэтому в точке перехода для теплоемкости и коэффициента расширения $\alpha(T)$ наблюдаются не разрывы, а скачки. На температурной зависимости $\alpha_{\mathrm{aver}}(T)$ в точке перехода второго рода наблюдаются слабые размытые изломы.

Влияние нагрева на относительное удлинение $\Delta L / L_{293 \mathrm{~K}}$, средний линейный коэффициент термического расширения $\alpha_{\text {aver }}$ и коэффициент термического расширения $\alpha(T)$ образца № 1 сульфида серебра показано на рис. 2.
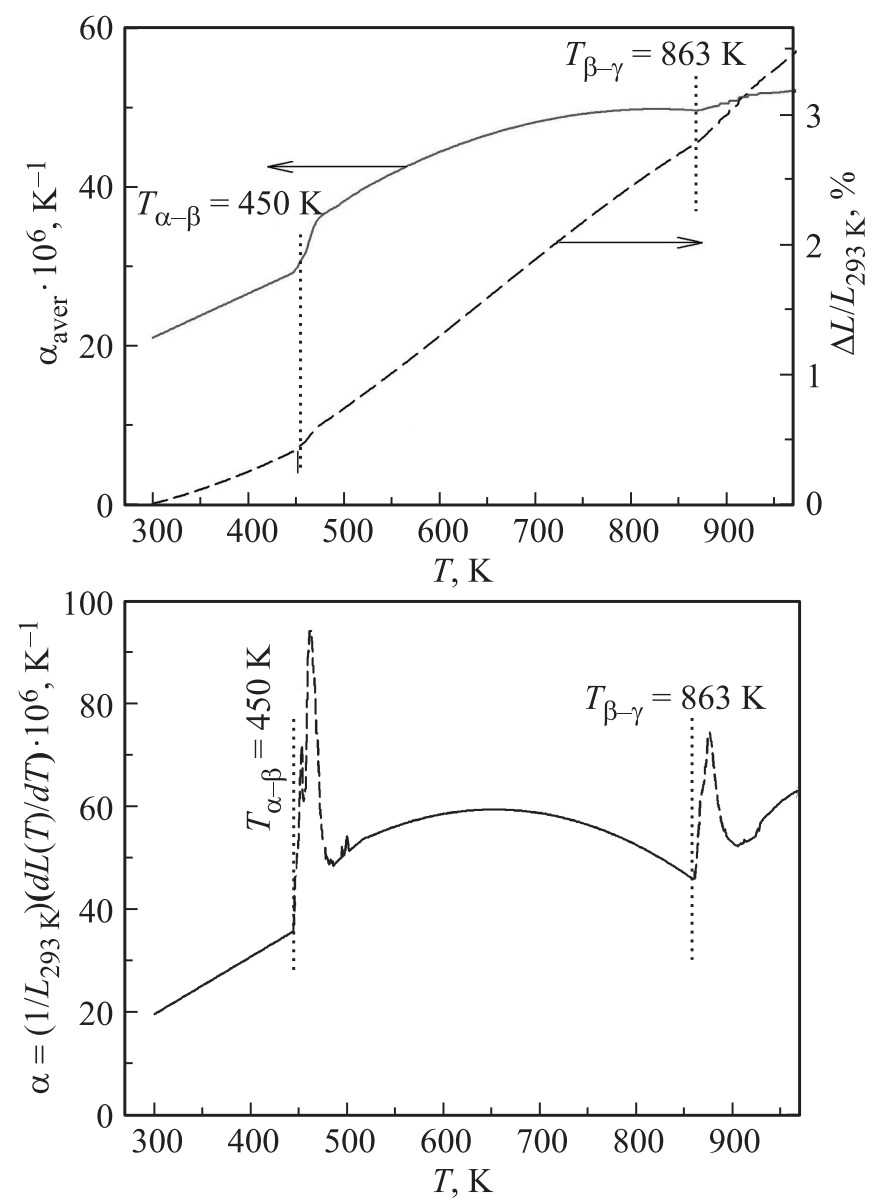

Рис. 4. Влияние температуры на относительное удлинение $\Delta L / L_{293 \mathrm{~K}}$, средний коэффициент термического расширения $\alpha_{\text {aver }}$ и коэффициент термического расширения $\alpha(T)$ нанокристаллического образца № 3. Области разрыва коэффициента $\alpha(T)$ показаны штриховыми линиями. Температуры переходов $T_{\alpha-\beta}$ и $T_{\gamma-\beta}$ отмечены вертикальными пунктирными линиями. Средний размер частиц в исходном порошке № 3 сульфида серебра равен $\sim 66 \mathrm{~nm}$. 
В области температур $293-455 \mathrm{~K}$, где существует акантит $\alpha-\mathrm{Ag}_{2} \mathrm{~S}, \alpha_{\text {aver }}$ увеличивается от $\sim 14.3 \cdot 10^{-6}$ до $\sim 18.9 \cdot 10^{-6} \mathrm{~K}^{-1}$. По величине это согласуется с данными $[13,18]$, свидетельствующими о том, что средний линейный коэффициент расширения $\alpha_{\text {aver }}$ акантита $\alpha-\mathrm{Ag}_{2} \mathrm{~S}$ в температурном интервале $300-433 \mathrm{~K}$ растет от $\sim 18.4 \cdot 10^{-6}$ до $\sim 24.0 \cdot 10^{-6} \mathrm{~K}^{-1}$, и с данными [19], согласно которым $\alpha_{\text {aver }}$ акантита равен $\sim 20 \cdot 10^{-6} \mathrm{~K}^{-1}$. При температуре от $\sim 500$ до $\sim 800 \mathrm{~K}$ в области существования аргентита $\beta-\mathrm{Ag}_{2} \mathrm{~S}$ средний коэффициент $\alpha_{\text {aver }}$ растет от $\sim 30.2 \cdot 10^{-6}$ до $\sim 42.1 \cdot 10^{-6} \mathrm{~K}^{-1}$. Далее, после превращения $\beta-\mathrm{Ag}_{2} \mathrm{~S}-\gamma-\mathrm{Ag}_{2} \mathrm{~S}$, коэффициент $\alpha_{\text {aver }}$ слабо увеличивается от $\sim 45.3 \cdot 10^{-6}$ до $\sim 45.9 \cdot 10^{-6} \mathrm{~K}^{-1}$ при повышении температуры от $\sim 900$ до $\sim 970 \mathrm{~K}$. На температурной зависимости среднего линейного коэффициента расширения $\alpha_{\text {aver }}(T)$ в окрестностях температур $T_{\alpha-\beta}$ или $T_{\beta-\gamma}$ наблюдаются размытые скачки (рис. 2).

Согласно $[13,18]$, средний коэффициент термического расширения $\alpha_{\text {aver }}$ аргентита при нагреве в области температур $443-623 \mathrm{~K}$ уменьшается от $\sim 55 \cdot 10^{-6}$ до $\sim 42 \cdot 10^{-6} \mathrm{~K}^{-1}$, тогда как по результатам настоящей работы $\alpha_{\text {aver }}$ аргентита в интервале температур $500-800 \mathrm{~K}$ медленно растет от $\sim 30 \cdot 10^{-6}$ до $\sim 42 \cdot 10^{-6} \mathrm{~K}^{-1}$. Отмеченное различие может быть обусловлено большим шагом измерения $(25-30 \mathrm{~K})$ коэффициента расширения в работах $[13,18]$ и, как следствие, фиксацией завышенной величины $\alpha_{\text {aver }}(443 \mathrm{~K})$ непосредственно в области фазового превращения, т.е. в области, где коэффициент расширения испытывает разрыв.

На зависимости $\alpha(T)$ в областях температур переходов $\alpha-\mathrm{Ag}_{2} \mathrm{~S}-\beta-\mathrm{Ag}_{2} \mathrm{~S}$ и $\beta-\mathrm{Ag}_{2} \mathrm{~S}-\gamma-\mathrm{Ag}_{2} \mathrm{~S}$ наблюдаются явные разрывы (рис. 2). Это позволило достаточно точно определить температуры переходов $T_{\alpha-\beta}=456 \pm 5 \mathrm{~K}$ и $T_{\beta-\gamma}=865 \pm 10 \mathrm{~K}$.

В целом характер изменения зависимостей $\alpha_{\text {aver }}(T)$ и $\alpha(T)$ (рис. 2) указывает на то, что превращения акантита $\alpha-\mathrm{Ag}_{2} \mathrm{~S}$ в аргентит $\beta-\mathrm{Ag}_{2} \mathrm{~S}$ и аргентита в фазу $\gamma-\mathrm{Ag}_{2} \mathrm{~S}$ происходят как фазовые переходы первого рода.

Изменения относительного удлинения $\Delta L / L_{293}$ K, среднего коэффициента термического расширения $\alpha_{\text {aver }}$ и коэффициента расширения $\alpha(T)$ при нагреве образца № 2 сульфида серебра (рис. 3) сходны с таковыми для образца № 1 (рис. 2). Однако температура перехода $T_{\beta-\gamma}$ для образца № 2 равна $833 \pm 10 \mathrm{~K}$, т. е. на $\sim 30 \mathrm{~K}$ меньше, чем для образца № 1. Размер частиц в исходном порошке № 2 равен $\sim 460 \mathrm{~nm}$, т.е. несколько больше, чем в порошке № 1 (см. таблицу).

Температурные зависимости относительного удлинения $\Delta L / L_{293}$ К и коэффициентов термического расширения $\alpha_{\text {aver }}$ и $\alpha$ для образца № 3 , полученного из нанокристаллического порошка № 3 сульфида серебра, показаны на рис. 4. Нагрев сопровождается ростом $\Delta L / L_{293}$ К и $\alpha_{\text {aver. }}$ На зависимости $\alpha(T)$ в областях превращений $\alpha-\mathrm{Ag}_{2} \mathrm{~S}-\beta-\mathrm{Ag}_{2} \mathrm{~S}$ и $\beta-\mathrm{Ag}_{2} \mathrm{~S}-\gamma-\mathrm{Ag}_{2} \mathrm{~S}$ наблюдаются явные разрывы (рис. 4). Температуры фазовых превращений

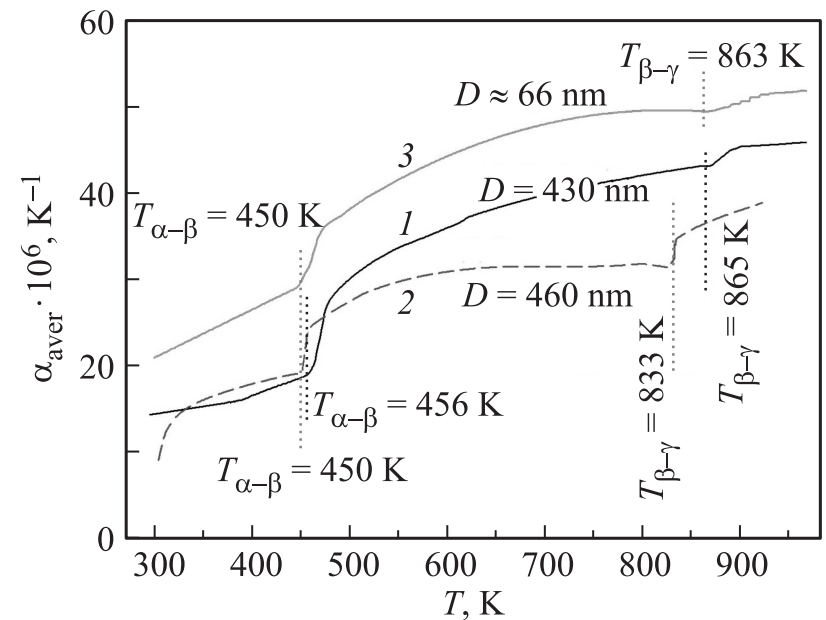

Рис. 5. Сравнение коэффициентов термического расширения

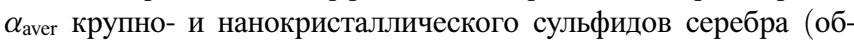
разцы № 1-3) в области температур 293-970 К. Номера кривых соответствуют номерам образцов в таблице.

равны $T_{\alpha-\beta}=450 \pm 5 \mathrm{~K}$ и $T_{\beta-\gamma}=863 \pm 20 \mathrm{~K}$ и близки к таковым для образца № 1 .

Для непосредственного сравнения теплового расширения крупно- и нанокристаллического сульфида серебра можно использовать средние коэффициенты линейного термического расширения $\alpha_{\text {aver }}$. Температурные зависимости коэффициентов $\alpha_{\text {aver }}(T)$ крупно- и нанокристаллического сульфида серебра показаны на рис. 5 . Во всем изученном интервале температур $293-970 \mathrm{~K}$ наибольший коэффициент $\alpha_{\text {aver }}(T)$ имеет нанокристаллический сульфид серебра (образец № 3), полученный из порошка со средним размером частиц $\sim 66 \mathrm{~nm}$. Наименьшая величина коэффициента $\alpha_{\text {aver }}(T)$ наблюдается для образца № 2, полученного из порошка с самым крупным средним размером частиц $460 \mathrm{~nm}$.

Съемка рентгенограмм образцов сульфида серебра при $293 \mathrm{~K}$ после измерения коэффициента термического расширения показала, что они по-прежнему являются однофазными и содержат только акантит $\alpha-\mathrm{Ag}_{2} \mathrm{~S}$. Благодаря достаточно высокой скорости нагрева продолжительность измерения не превышала $3 \mathrm{~h}$, и размер частиц $\mathrm{Ag}_{2} \mathrm{~S}$ в образцах после измерения увеличился не более чем на $10 \mathrm{~nm}$.

\section{4. Теплоемкость сульфида серебра}

С помощью дифференциальной сканирующей калориметрии нанокристаллического порошка № 4, совмещенной с термогравиметрическим измерением, было обнаружено, что при нагреве нанопорошка до $\sim 1000 \mathrm{~K}$ наблюдается потеря массы $\sim 1.0-1.5 \%$. Измерения показали, что убыль массы, наблюдаемая в областях температур $430-510$ и $670-730 \mathrm{~K}$, связана с выделением серы и образованием $\mathrm{SO}_{2}$. Убыль массы, наблюдаемая при температуре $\sim 570 \mathrm{~K}$, обусловлена выделением $\mathrm{CO}_{2}$ 
вследствие окисления углерода. Источниками серы и углерода в синтезированных порошках сульфида серебра являются примеси исходных реагентов $\mathrm{Na}_{2} \mathrm{~S}$ и $\mathrm{Na}_{3} \mathrm{Cit}$. Растворы сульфида и цитрата натрия адсорбируются поверхностью порошков $\mathrm{Ag}_{2} \mathrm{~S}$ при их осаждении, и малые количества этих примесей сохраняются в синтезированных порошках сульфида серебра даже после промывания.

Для того чтобы избежать ошибок в определении теплоемкости, связанных с выделением примесей $\mathrm{S}$ и $\mathrm{C}$ из порошков $\mathrm{Ag}_{2} \mathrm{~S}$, порошки предварительно отжигались в аргоне при нагреве до $970 \mathrm{~K}$ и затем охлаждались. По данным рентгеновской дифракции отожженные порошки сульфида серебра остаются однофазными и содержат только акантит $\alpha-\mathrm{Ag}_{2} \mathrm{~S}$, по данным БЭТ и рентгеновской дифракции размер частиц порошков почти не увеличивается.

Теплоемкость измерялись на отожженных порошках. Температурный интервал измерения разделялся на участки 300-450, 470-840 и 870-970 K, соответствующие равновесным фазам $\alpha-\mathrm{Ag}_{2} \mathrm{~S}, \beta-\mathrm{Ag}_{2} \mathrm{~S}$ и $\gamma-\mathrm{Ag}_{2} \mathrm{~S}$, и участки $450-470$ и $840-870 \mathrm{~K}$ в окрестностях температур превращений $T_{\alpha-\beta}$ и $T_{\beta-\gamma}$.

Теплоемкость порошка № 4 сульфида серебра, за исключением областей перехода, достаточно монотонно меняется с ростом температуры (рис. 6). В интервале температур 300-450 K теплоемкость увеличивается, затем испытывает разрыв вблизи температуры превращения $T_{\alpha-\beta}$. В области существования фазы $\beta-\mathrm{Ag}_{2} \mathrm{~S}$ при температуре от $\sim 470$ до $\sim 840 \mathrm{~K}$ теплоемкость сначала слабо понижается до температуры $\sim 670 \mathrm{~K}$, а затем слабо растет вплоть до температуры превращения $T_{\beta-\gamma}$, где испытывает разрыв. При дальнейшем увеличении температуры до $\sim 910 \mathrm{~K}$ наблюдается небольшое понижение теплоемкости. По результатам измерения теплоемкости температуры превращений $T_{\alpha-\beta}$ и $T_{\beta-\gamma}$ равны 451 и $858 \mathrm{~K}$, что согласуется с данными, полученными при измерении теплового расширения сульфида серебра.

Пики теплоемкости $C_{p}$ нанопорошка сульфида серебра в области превращений $\alpha-\mathrm{Ag}_{2} \mathrm{~S}-\beta-\mathrm{Ag}_{2} \mathrm{~S}$ и $\beta-\mathrm{Ag}_{2} \mathrm{~S}-\gamma-\mathrm{Ag}_{2} \mathrm{~S}$ имеют скорее симметричную (рис. 6, вставка), а не $\lambda$-образную форму. Симметричная форма наблюдаемых пиков характерна для фазовых переходов первого рода. Пики теплоемкости узкие (ширина в основании составляет $\sim 8 \mathrm{~K})$, что также типично для фазовых переходов первого рода.

Оценка энтальпии фазовых превращений $\alpha-\mathrm{Ag}_{2} \mathrm{~S}-$ $\beta-\mathrm{Ag}_{2} \mathrm{~S}$ и $\beta-\mathrm{Ag}_{2} \mathrm{~S}-\gamma-\mathrm{Ag}_{2} \mathrm{~S}$ дала величины $\Delta H_{\alpha-\beta}=$ $=4.2 \pm 0.4 \mathrm{~kJ} \cdot \mathrm{mol}^{-1}$ и $\Delta H_{\beta-\gamma}=1.2 \pm 0.3 \mathrm{~kJ} \cdot \mathrm{mol}^{-1}$ coответственно. В пределах ошибок измерений найденные величины энтальпий фазовых превращений $\Delta H_{\alpha-\beta} \quad$ и $\Delta H_{\beta-\gamma}$ довольно близки к приведенным в литературе. По литературным данным энтальпия $\Delta H_{\alpha-\beta}$ равна $3.98[14], 4.06 \quad[15], 3.93 \quad[16]$ и $3.7-3.9 \mathrm{~kJ} \cdot \mathrm{mol}^{-1}[12,13,17]$. Согласно [15] и [16], эн-

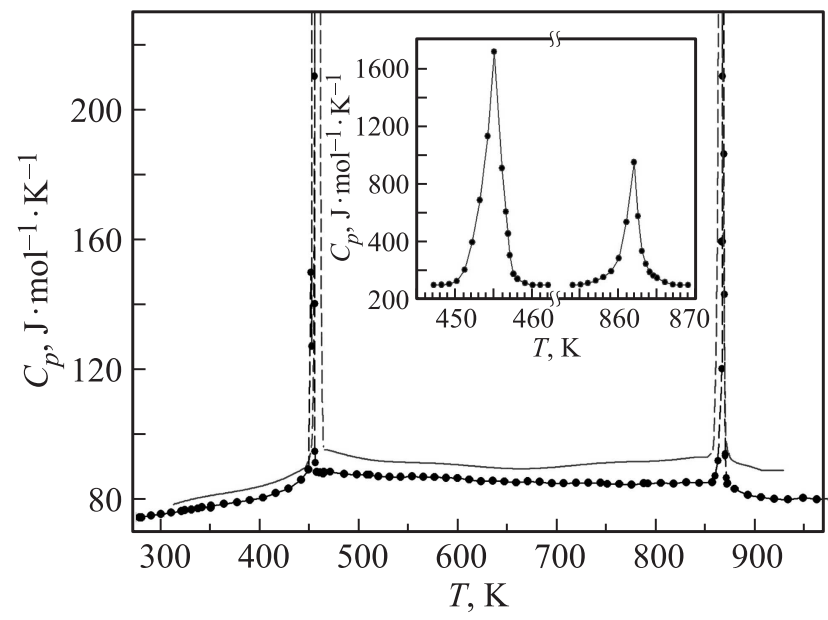

Рис. 6. Молярная теплоемкость $C_{p}$ нанопорошка № 4 сульфида серебра $\mathrm{Ag}_{2} \mathrm{~S}$. Точками для сравнения показана теплоемкость крупнозернистого сульфида серебра [15]. На вставке скачкообразное изменение $C_{p}$ нанопорошка $\mathrm{Ag}_{2} \mathrm{~S}$ в области превращений $\alpha-\mathrm{Ag}_{2} \mathrm{~S}-\beta-\mathrm{Ag}_{2} \mathrm{~S}$ и $\beta-\mathrm{Ag}_{2} \mathrm{~S}-\gamma-\mathrm{Ag}_{2} \mathrm{~S}$.

тальпия $\Delta H_{\beta-\gamma}$ превращения аргентита $\beta-\mathrm{Ag}_{2} \mathrm{~S}$ в фазу $\gamma-\mathrm{Ag}_{2} \mathrm{~S}$ равна $\sim 0.78$ и $\sim 0.50 \mathrm{~kJ} \cdot \mathrm{mol}^{-1}$ соответственно.

Для сравнения на рис. 6 представлены наиболее надежные экспериментальные данные по теплоемкости крупнозернистого $\mathrm{Ag}_{2} \mathrm{~S}$ [15], полученные методом адиабатической калориметрии. Моноклинный сульфид серебра в работе [15] был получен непосредственным спеканием порошков серебра и серы при температуре до $770 \mathrm{~K}$ в течение 11 дней. При таком методе синтеза размер кристаллитов в образце составлял более $5 \mu \mathrm{m}$.

Хорошо видно, что во всей области температур теплоемкость нанокристаллического сульфида серебра $\mathrm{Ag}_{2} \mathrm{~S}$, измеренная в настоящей работе, на $1-4 \%$ больше теплоемкости крупнозернистого сульфида [15]. Измеренные пики теплоемкости $C_{p}$ нанопорошка сульфида серебра несколько уширены по температуре по сравнению с полученными в работе [15] для крупнозернистого $\mathrm{Ag}_{2} \mathrm{~S}$.

Ранее теплоемкость нанокристаллического сульфида серебра никто не измерял. Тем не менее имеются сведения о зависимости теплоемкости металлов от размера частиц, полученные при низких температурах. Так, в работе [30] установлено, что удельная теплоемкость нанокристаллического серебра $\mathrm{Ag}$, измеренная при температуре от 1 до $10 \mathrm{~K}$, больше теплоемкости массивного серебра. По данным [31,32] в области температур $14-30 \mathrm{~K}$ теплоемкость палладия со средним размером частиц $\sim 7-8 \mathrm{~nm}$ заметно больше теплоемкости массивного палладия. Согласно [33], теплоемкость наночастиц меди при температуре $300-450 \mathrm{~K}$ в $\sim 1.2-1.6$ раза больше теплоемкости массивной меди.

В работах $[13,18,34,35]$ показано, что малый размер частиц вносит положительный вклад в теплоемкость и средний коэффициент термического расширения сульфидов серебра и свинца. 
Согласно [34], основной причиной изменения решеточных свойств нанокристаллов по сравнению с характерными для объемного крупнозернистого вещества являются изменения вида фононного спектра и его границ, т.е. изменение функции распределения частот атомных колебаний.

Основная идея большинства моделей модификации фононного спектра малых частиц или наноструктурированных систем состоит в появлении в фононном спектре низкочастотных мод, которые отсутствуют в спектре объемного крупнозернистого (bulk) кристалла [27]. Фононный спектр малых частиц сильно отличается от такового для массивного вещества, как показано авторами работ [36,37] и многими другими. Согласно [27,38], в наночастицах могут возникать волны, длина которых не превышает удвоенный наибольший размер частицы $D$, т. е. $\lambda \leq 2 D$, поэтому со стороны низкочастотных колебаний фононный спектр ограничен некоторой минимальной частотой $\omega_{\min } \geq 2 \pi \frac{c_{t}}{2 D}$, где $c_{t}$ - скорость распространения поперечных упругих колебаний (поперечная скорость звука). В объемных (bulk) кристаллах такого ограничения нет. Кроме того, фононный спектр ограничен со стороны высоких частот. С учетом этих ограничений молярная теплоемкость вещества, молекула которого содержит $n$ атомов, равна

$$
C_{V}(T)=n \int_{\omega_{\min }}^{\omega_{\max }} \frac{\partial \varepsilon(\omega, T)}{\partial T} g(\omega) d \omega .
$$

В [34,39] с учетом ограничений фононного спектра малых частиц и с использованием приближения [40] для верхней границы $\omega_{\max }$ фононного спектра было показано, что молярную теплоемкость (4) нанокристаллического вещества с частицами прямоугольной формы можно записать как функцию не только температуры $T$, но и размера $D$ малой частицы

$$
C_{V}(T, D)=C_{V}^{\text {bulk }}(T)+n\left(k_{1} L_{\Sigma} T+k_{2} S_{\Sigma} T^{2}\right),
$$

где первый член есть дебаевская теплоемкость крупнозернистого (bulk) кристалла в низкотемпературной области, $L_{\Sigma}$ и $S_{\Sigma}$ - общая длина ребер и общая площадь поверхности малых частиц. Если принять, что малые частицы имеют форму куба с ребрами длиной $D$, то число таких частиц, содержащихся в объеме $v_{m}$, равно $n_{p}=v_{m} / D^{3}$. В этом случае $L_{\Sigma}=12 n_{p} D=12 v_{m} / D^{2}$ и $S_{\Sigma}=6 n_{p} D^{2}=6 v_{m} / D$. Величины $k_{1}=\left(k_{\mathrm{B}}^{2} c_{1}^{-1} / 8 \pi \hbar\right) I_{2}$ и $k_{2}=\left(k_{\mathrm{B}}^{3} c_{2}^{-1} / 2 \pi \hbar^{2}\right) I_{3}-$ положительные постоянные, $I_{m}=\left(4 m ! / 2^{m+1}\right) \sum_{N=1}^{\infty} N^{-m} \equiv\left(4 m ! / 2^{m+1}\right) \xi(m), \quad \xi(m) \quad-$ дзета-функция Римана $\left(I_{3}=1.8031, I_{2}=\pi^{2} / 6\right), c_{1}^{-1}$ и $c_{2}^{-1}$ - эффективные скорости упругих колебаний, определяемые через скорости продольных $c_{l}$ и поперечных $c_{t} \quad$ колебаний: $c_{1}^{-1}=c_{l}^{-1}+2 c_{t}^{-1} \quad$ и $c_{2}^{-1}=\frac{2 c_{t}^{4}-3 c_{t}^{2} c_{l}^{2}+3 c_{l}^{4}}{c_{t}^{2} c_{l}^{2}\left(c_{l}^{2}-c_{t}^{2}\right)}$.
С учетом (3), (5) и выражений для $L_{\Sigma}$ и $S_{\Sigma}$ коэффициент термического расширения нанокристаллического вещества можно представить как

$$
\begin{aligned}
\alpha(T, D) & =\frac{\gamma C_{V(\text { bulk })}(T)}{3 v_{m} B}+n \frac{\gamma}{3 v_{m} B}\left(k_{1} L_{\Sigma} T+k_{2} S_{\Sigma} T^{2}\right) \\
& =\alpha_{\text {bulk }}(T)+n \frac{\gamma}{3 B}\left(\frac{12 k_{1} T}{D^{2}}+\frac{6 k_{2} T^{2}}{D}\right) .
\end{aligned}
$$

Таким образом, теплоемкость и коэффициент термического расширения нанокристаллического вещества включают дополнительный положительный вклад по сравнению с этими же свойствами крупнозернистого (bulk) вещества. Именно такой результат наблюдается в настоящей работе для теплоемкости и коэффициента термического расширения нанокристаллического сульфида серебра $\mathrm{Ag}_{2} \mathrm{~S}$. Появление положительного вклада обусловлено ограничением фононного спектра со стороны низких и высоких частот.

Кроме того, уменьшение размера частиц сульфида серебра должно сопровождаться увеличением ангармонизма атомных колебаний $[13,18]$. Это согласуется с выводами [27,34] о существенном увеличении роли ангармонизма тепловых колебаний для наноматериалов по сравнению с макроструктурами. В целом данные настоящей работы и предшествующие результаты $[18,19,34]$ показывают, что уменьшение частиц сульфида серебра до наноразмерного масштаба приводит к повышенным величинам теплоемкости $C_{p}$ и коэффициента термического расширения $\alpha_{\text {aver }}$ при сопоставимой температуре.

Результаты настоящей работы и калориметрических, термохимических и ДТА-исследований [14-19] показывают, что превращения $\alpha-\mathrm{Ag}_{2} \mathrm{~S}-\beta-\mathrm{Ag}_{2} \mathrm{~S} \quad$ и $\beta-\mathrm{Ag}_{2} \mathrm{~S}-\gamma-\mathrm{Ag}_{2} \mathrm{~S}$ происходят по механизму фазового перехода первого рода. Найденные температуры $T_{\alpha-\beta}=452 \pm 2 \mathrm{~K} \quad$ и $\quad T_{\beta-\gamma}=863 \pm 3 \mathrm{~K} \quad$ и $\quad$ энтальпии $\Delta H_{\alpha-\beta}=4.2 \pm 0.4 \mathrm{~kJ} \cdot \mathrm{mol}^{-1}$ и $\Delta H_{\beta-\gamma}=1.2 \pm 0.3 \mathrm{~kJ} \cdot \mathrm{mol}^{-1}$ фазовых превращений хорошо согласуются с литературными данными [12-18].

\section{5. Заключение}

Средний коэффициент линейного термического расширения $\alpha_{\text {aver }}$ нанокристаллического сульфида серебра $\mathrm{Ag}_{2} \mathrm{~S}$ в области температур $\sim 300-970 \mathrm{~K}$ больше, чем $\alpha_{\text {aver }}$ крупнокристаллического сульфида серебра. Теплоемкость $C_{p}$ нанокристаллического сульфида серебpa в этой же области температур на $1-4 \%$ больше, чем $C_{p}$ крупнокристаллического сульфида. Наблюдаемая разница коэффициентов термического расширения и теплоемкостей обусловлена малым размером частиц $\mathrm{Ag}_{2} \mathrm{~S}$ в нанокристаллическом сульфиде серебра. Наличие разрывов на температурных зависимостях $\alpha(T)$ и $C_{p}(T)$ в окрестностях температур превращений акантит $\alpha-\mathrm{Ag}_{2} \mathrm{~S}$-аргентит $\beta-\mathrm{Ag}_{2} \mathrm{~S}$ и аргентит $\beta-\mathrm{Ag}_{2} \mathrm{~S}$-фаза 
$\gamma-\mathrm{Ag}_{2} \mathrm{~S}$ свидетельствует о том, что эти превращения происходят по механизму фазовых переходов первого рода.

Авторы благодарят О.Н. Леонидову и Д.А. Ягодина за помощь в дилатометрических и калориметрических измерениях.

\section{Список литературы}

[1] M.M. El-Nahass, A.A.M. Farag, E.M. Ibrahim, S. Abd-ElRahman. Vacuum 72, 4, 453 (2004).

[2] V.B. Prabhune, N.S. Shinde, V.J. Fulari. Appl. Surf. Sci. 255, 5, 1819 (2008).

[3] U.M. Jadhav, S.N. Patel, R.S. Patil. Res. J. Chem. Sci. 3, 7, 69 (2013).

[4] V. Krylova, A. Milbrat, A. Embrechts, J. Baltrusaitis. Appl. Surf. Sci. 301, 134 (2014).

[5] D. Karashanova, D. Nihtianova, K. Starbova, N. Starbov. Solid State Ion. 171, 3-4, 269 (2004).

[6] R. Zamiri, H.A. Ahangar, A. Zakaria, G. Zamiri, M. Shabani, B. Singh, J.M.F. Ferreira. Chem. Centr. J. 9, 28 (2015).

[7] R.S. Sharma, Y.A. Chang. Bull. Alloy Phase Diagrams 7, 3, 263 (1986).

[8] R. Sadanaga, S. Sueno. Mineralog. J. Jpn. 5, 2, 124 (1967).

[9] S.I. Sadovnikov, A.I. Gusev, A.A. Rempel. Superlatt. Microstruct. 83, 35 (2015).

[10] S.I. Sadovnikov, A.I. Gusev, A.A. Rempel. Phys. Chem. Chem. Phys. 17, 19, 12466 (2015).

[11] T. Blanton, S. Misture, N. Dontula, S. Zdzieszynski. Powder Diffract. 26, 2, 110 (2011).

[12] S.I. Sadovnikov, A.I. Gusev, A.A. Rempel. Phys. Chem. Chem. Phys. 17, 32, 20495 (2015).

[13] S.I. Sadovnikov, A.I. Gusev, A.V. Chukin, A.A. Rempel. Phys. Chem. Chem. Phys. 18, 6, 4617 (2016).

[14] C.M. Perrott, N.H. Fletcher. J. Chem. Phys. 50, 6, 2344 (1969).

[15] F. Grønvold, E.F. Westrum. J. Chem. Therm. 18, 4, 381 (1986).

[16] W.T. Thompson, S.N. Flengas. Can. J. Chem. 49, 9, 1550 (1971).

[17] С.И. Садовников, А.В. Чукин, А.А. Ремпель, А.И. Гусев. ФTT 58, 1, 32 (2016).

[18] А.И. Гусев, С.И. Садовников, А.В. Чукин, А.А. Ремпель. ФTT 58, 2, 246 (2016).

[19] H. Okazaki, A. Takano. Z. Naturforsch. A 40, 10, 986 (1985).

[20] K. Honma, K. Iida. J. Phys. Soc. Jpn. 56, 5, 1828 (1987).

[21] С.И. Садовников, А.А. Ремпель. Неорган. материалы 51, 8 , 829 (2015).

[22] S.I. Sadovnikov, A.I. Gusev. Eur. J. Inorg. Chem. 2016, 31, 4944 (2016).

[23] Н.С. Кожевникова, С.И. Садовников, А.А. Ремпель. ЖОХ 81, 10, 1608 (2011)

[24] X'Pert HighScore Plus. Version 2.2e (2.2.5). (c) 2009 PANalytical B.V. Almedo, the Netherlands.

[25] С.И. Садовников, Н.С. Кожевникова, В.Г. Пушин, А.А. Ремпель. Неорган. материалы 48, 1, 26 (2012).

[26] С.И. Садовников, Н.С. Кожевникова. ФТТ 54, 8, 1459 (2012).

[27] A.I. Gusev, A.A. Rempel. Nanocrystalline materials. Cambridge Intern. Science Publ., Cambridge (2004). 351 p.

[28] S.I. Sadovnikov, A.I. Gusev. J. Alloys Compd. 586, 105 (2014).
[29] N.W. Ashcroft, N.D. Mermin. Solid state physics. Cornell University, N.Y.-Chicago-London (1976). 826 p.

[30] G. Goll, H. Löhneyen. Nanostruct. Mater. 6, 5-8, 559 (1995).

[31] G.H. Comsa, D. Heitkamp, H.S. Räde. Solid State Commun. 24, 8, 547 (1977).

[32] Y.Y. Chen, Y.D. Yao, S.U. Jen, B.T. Lin, H.M. Lin, C.Y. Tung, S.S. Hsiao. Nanostruct. Mater. 6, 5-8, 605 (1995).

[33] Y.Y. Chen, Y.D. Yao, B.T. Lin, C.T. Suo, S.G. Shyu, H.M. Lin. Nanostruct. Mater. 6, 5-8, 597 (1995).

[34] S.I. Sadovnikov, A.I. Gusev. J. Alloys Compd. 610, 196 (2014).

[35] С.И. Садовников, А.И. Гусев, А.А. Ремпель. Успехи химии 85, 7, 731 (2016).

[36] J.M. Dickey, A. Paskin. Phys. Rev. B 1, 2, 851 (1970).

[37] P.M. Ajayan, L.D. Marks. Phase Trans. 24-26, Sect. B, pt. 1, 229 (1990).

[38] Ю.И. Петров. Физика малых частиц. Наука, М. (1982). $360 \mathrm{c}$.

[39] С.И. Садовников, А.И. Гусев. ФТТ 56, 11, 2274 (2014).

[40] E.W. Montrol. J. Chem. Phys. 18, 2, 183 (1950). 